\title{
LA REVOLUCIÓN MEXICANA (REVISITADA) Y LA LEGITIMACIÓN DEL ESTADO
}

YOLANDA PADILLA RANGEL

Departamento de Historia/UAA

Víctor M. González Esparza, Cambio y continuidad. La Revolución mexicana en Aguascalientes, Centro de Investigaciones y Estudios Multidisciplinarios de Aguascalientes/Oficina de la Coordinación de Asesores de Gobierno del Estado, Aguascalientes, México, 1998.

íctor González Esparza es un historiador aguascalentense formado en la UNAM, el Instituto José María Luis Mora y la Universidad de Tulane, New Orleans. No solamente su formación académica es sólida y amplia, sino que también cuenta con una gran experiencia de investigación, de la cual podríamos destacar sus periodos de trabajo en el Centro de Investigación y Docencia Económica, en la Universidad Autónoma de Aguascalientes y, rècientemente, en la Oficina de Coordinación de Asesores del Gobierno del Estado. Además, Víctor pertenece a la primera generación de historiadores profesionales que se desempeñan (nos desempeñamos) en el estado de Aguascalientes, habiendo tenido como pionera a Beatriz Rojas. Como historiador, Víctor González ha publicado varios productos de investigación, ${ }^{1}$ en los cuales, cualquier lector puede constatar su seriedad profesional, su gran capacidad de análisis y su amplitud de miras. En su vasto horizonte cultural, destaca su interés por la historia del siglo XX, particularmente, la historia de la revolución, de la familia y de las políticas sociales del estado postrevolucionario. Estamos, pues, ante el caso de un historiador que ha sostenido un esfuerzo intelectual en el ámbito de la historia social, que el Sistema Nacional de Investigadores se ha en-

1 Entre los que destaca su libro Jalones modernizadores, Aguascalientes en el siglo XX, publicado por el Instituto Cultural de Aguascalientes en 1992. 
cargado de reconocer al integrarlo entre sus miembros. Por otra parte, Víctor tiene cualidades intelectuales (agudo, crítico, abierto, tolerante) y de personalidad (amistoso, cordial, equilibrado, conciliador) que pueden propiciar un debate académico de buen nivel. Debate que, desde mi punto de vista, hace falta cultivar en el medio mexicano con más rigurosidad y, a la vez, cordialidad. Al igual que Víctor González, mi colega y amigo, y citando a Karl Popper, considero que el conocimiento es un ejercicio crítico, más allá de cuestiones personales, lo que implica que el conocimiento es una creación colectiva.

En el libro que aquí reseño, Víctor nos ofrece una parte de la tesis que presentó para obtener el grado de doctor en Historia de América Latina por la Universidad de Tulane. En esta ocasión, más que un producto de investigación histórica, el libro ofrece un ensayo de interpretación sobre la revolución mexicana en general, aunque hace énfasis particular en una expresión concreta de la misma, como lo es el caso del estado de Aguascalientes. El carácter de ensayo viene dado por el constante esfuerzo de interpretación que el autor sostiene de principio a fin, ubicándose en los efectos de la revolución en el largo plazo, argumentando sus propias ideas y fundamentándolas históricamente. Así también, se trata de un ensayo por el predominio de la consulta a fuentes secundarias más que primarias, debiéndose destacar la abundancia de lecturas actualizadas en textos históricos y demográficos.

Me interesa destacar sobre este libro el esquema de interpretación de la Revolución Mexicana que se propone, que pretende rebasar versiones localistas, tomando más bien a la región (en este caso el estado de Aguascalientes) como un pretexto para pensar en eventos nacionales y problemas históricos complejos. Aunque su interpretación no es novedosa, sí es todavía polémica. Además, la actitud combativa contra el localismo, el revisionismo y el caciquismo que el autor adopta a lo largo del texto constituye, desde mi punto de vista, una invitación al debate.

\section{CONTRA EL LOCALISMO, LA TEORIZACIÓN}

Los estudios regionales, que introdujeron la diversidad en una historia nacional vista hasta entonces uniformemente, han proliferado en las últimas décadas en México. Víctor Gonzalez señala que comenzaron como una especie de venganza contra la centralización y que, en determinado momento, se volvieron ciegos a las perspectivas teóricas y los procesos nacionales. En algunos casos, dice, se cayó en un viejo provincianismo justifi- 
cador de cacicazgos, inclusive la antigua tradición antropológica de estudios locales cayó en algunos de estos excesos, ya que, en un momento dado, se atrevió también a cuestionar la intervención estatal en el campo.

“Tal vez, Víctor González tenga algo de razón, pero no toda. Considero que los estudios regionales han enriquecido y aún siguen enriqueciendo las historiografías regionales, la nacional y en general a la historia -a secas- (y no sólo al revisionismo como señala Víctor). No creo que sus potencialidades estén agotadas. Sin embargo, el autor pretende no caer en el localismo, ni en la revancha descentralizadora, ni en el provincianismo. Además, pretende entender la Revolución Mexicana "en toda su dimensión" y aplicar un esquema de interpretación para el caso de Aguascalientes.

Con un esquema interpretativo que podría ubicarse como "neopopulista" -la Revolución fue hecha por las masas campesinas y representa un impulso transformador más "desde abajo" que "desde arriba"- el autor pretende interpretar lo ocurrido en el estado de Aguascalientes durante la revolución mexicana. Sin embargo, es sabido que en este estado no hubo brotes armados. La revolución maderista provocó agitación política entre los trabajadores del ferrocarril y en las élites políticas, mientras que los norteños, y en particular los villistas, pasaron por Aguascalientes reclutando algunos campesinos. Aguascalientes fue sede de la Convención de 1914 - precisamente por ser considerado un lugar neutral-y experimentó los efectos desastrosos del paso de los revolucionarios por la entidad, así como los efectos del triunfo constitucionalista. A pesar de todo ello, creo que Aguascalientes pertenece más a las regiones revolucionadas (concepto de Luis González) que a las revolucionarias. Entonces, el punto de partida de Víctor es resbaladizo, ya que la Revolución se vivió en Aguascalientes más como una agitación partidaria y de cambios en las élites gobernantes que como una insurrección popular. El caso de Aguascalientes, creo que debe analizarse históricamente aún más, en vez de tratar de ubicarlo ya en la premisa global de que la Revolución Mexicana fue popular y agrarista. La revolución, como dice Víctor, son varias revoluciones; entonces, ¿por qué tratar de meter a todas en el mismo "saco" interpretativo? Creo que una interpretación sintética de la revolución -a nivel nacional- como la que pretende Víctor González debe considerar y reconocer la diversidad y las especificidades regionales del país, retomando las aportaciones de la historiografía regional. 
Aguascalientes fue un estado con poco movimiento campesino, con una débil organización agrarista (en todo caso, ésta era eventual, dependiendo de la fuerza política de los agraristas en el centro del país). En este estado se expresó con más fuerza el movimiento cristero que el movimiento agrarista, por lo que no me parece muy acertado el esquema interpretativo de Víctor González. En cambio, sí me parece acertado el análisis de la propiedad de la tierra y el esfuerzo que emprende por entender la relación entre propiedad, tierra y sociedad a principios del siglo XX en Aguascalientes.

El autor propone que en Aguascalientes, desde el Porfiriato, la propiedad de la tierra estaba muy concentrada en pocas manos, a pesar de la existencia cada vez mayor de arrendatarios y medieros. Éstos, al no ser propietarios, no generaron un cambio en el esquema monopólico de la tenencia de la tierra. Víctor observa la tendencia documentada anteriormente por Jesús Gómez ${ }^{2}$ y Beatriz Rojas, ${ }^{3}$ en el sentido de que la gran propiedad se estaba fragmentando desde el siglo XIX y propone que, en efecto, la propiedad se dividía pero que, aún así, la mejor tierra estaba concentrada en pocas manos. Argumenta que fueron los campesinos los actores que propiciaron la división de la tierra, encabezados por el Estado. "La revolución, dice, descubrió a los campesinos, no como carne de cañón y sujetos manipulables, sino como actores sociales relevantes". Me parece que el autor idealiza un poco a los campesinos, particularmente a los agraristas. La reforma agraria en Aguascalientes, desde mi punto de vista, fue una reforma impulsada desde el Estado central, muchas veces en forma vertical, elaborando las demandas de tierra más desde un escritorio en la ciudad de México que desde el campo hidrocálido. Por otra parte, los campesinos agraristas, particularmente durante el movimiento cristero, sí fueron utilizados por el ejército federal para combatir a los cristeros. Considero que, si se trata de romanticismos, no solamente se le puede cuestionar al revisionismo el idealizar a los cristeros o a las comunidades campesinas holísticas. También al neorevisionismo se le puede cuestionar su idealización del movimiento agrario y del Estado modernizador.

2 Jesús Gómez Serrano, Aguascalientes en la historia, 1786-1920, Tomo II, México, Gobierno del Estado de Aguascalientes/ Instituto de Investigaciones Dr. José María Luis Mora, 1988.

3 Beatriz Rojas, La destrucción de la hacienda en Aguascalientes,1910-1931, Zamora, El Colegio de Michoacán, 1981. 
El campesinado de Aguascalientes (y podemos decir que del país entero) no fue ni ha sido homogéneo. Así, en diferentes momentos del movimiento revolucionario, particularmente durante la Cristiada, coexistieron y se expresaron dos realidades: la de los campesinos agraristas y la de los campesinos no agraristas o cristeros. En todo caso, fue un periodo de luchas fratricidas por cuestiones agrarias pero, también, por otros motivos, como la defensa de prácticas culturales como las católicas.

Así pues, contra la historia localista, que se refiere unicamente a Aguascalientes, Víctor utiliza el arma de la teoría: la teoría de la Revolución. Para él, las revoluciones son algo más que violencia, manipulación y oportunismo y hay que verlas en su contexto estructural. La Revolución Mexicana, en esta visión, dio un impulso al Estado moderno y centralizador que surgió en México desde el siglo XIX. El Estado postrevolucionario aparece entonces como el héroe de la Revolución Mexicana, el impulsor del progreso económico, el actor principal de la justicia social. Cabe hacer notar que, aunque esta visión de la historia se proyecta desde el antirevisionismo, se parece mucho a la versión de la Revolución Mexicana defendida por el nacionalismo revolucionario.
CONTRA EL REVISIONISMO, LA LEGITIMACIÓN del Estado Mexicano

Fue en los años setenta cuando el revisionismo cuestionó aquella vieja ortodoxia del nacionalismo revolucionario que comenzó el debate. Fue cuando, según Víctor, "todo se puso de cabeza", y por lo tanto había que ponerlo (al discurso historiográfico) en su posición original: la Revolución Mexicana fue netamente popular, propició un Estado centralizador que liberó a las regiones de sus cacicazgos y fue el realizador de la justicia social. Sin embargo, a diferencia de la ortodoxia revolucionaria, la visión de Víctor no es simple. Lo que él hace es recuperar viejos temas, aunque con un nuevo enfoque y con nueva información.

Para escapar al revisionismo Víctor busca tener, como ya dijimos, una visión estructural y, además, con una propuesta novedosa: integrar en ella los avances de la nueva historia demográfica. Un argumento central del autor es que fueron los cambios demográficos (particularmente la presión que ejercieron los campesinos sin tierra y los hijos de la élite sin posición) el elemento clave para explicar la Revolución en Aguascalientes. El problema de fondo, en esta nueva lectura del fenómeno revolucionario es la capacidad 
de los estados nacionales para enfrentar no solamente la presión demográfica, sino también los cambios sociales y económicos desencadenados por ésta.

El autor argumenta que en Aguascalientes fue la concentración de la propiedä, junto con la presión de los campesinos sin tierra, lo que originó la Revolución. Ya mencioné que el caso Aguascalientes parece ser algo fallido para ejemplificar históricamente este argumento. Sin embargo, en este momento quiero referirme más bien a otro problema, no de tipo histórico sino epistemológico: la premisa de la que se parte (la concentración de la tierra y la presión demográfica originaron la Revolución) es idéntica a la conclusión. Yo pregunto si la actitud combativa ante el revisionismo y la armadura teórica del ensayo no le impidieron al autor mostrar una mayor apertura hacia la realidad histórica. Si así fuera, estaríamos ante el caso de un ensayo histórico más preocupado por combatir, comprobar tesis y argumentar en torno a ellas que por comprender los hechos históricos en su propia especificidad.

Sin embargo, el autor demuestra en forma excelente su oficio de historiador, particularmente en el apartado que habla de la "crisis del hambre", suscitada en Aguascalientes en 1916, ya que en él se observa la mayor fundamentación históri- ca de todos los argumentos que formula, entre paréntesis, de una manera formidablemente lógica y ordenada. Sin embargo, de este apartado no es muy convincente el argumento de que la crisis del hambre no la causó la agitación revolucionaria, si consideramos que fue ésta la que hizo parar fábricas e intervenir haciendas, lo cual provocó escasez, especulación y hambre, problemas que, finalmente, incidieron en la propensión de la población a la enfermedad y la mortandad.

\section{CONTRA EL CACICAZGO, \\ EL ESTADO CENTRALIZADOR}

Un problema histórico que le incomoda al autor, junto con el de la concentración de la propiedad, es el del cacicazgo. Sin embargo, en Aguascalientes no se observó un tipo de cacicazgo poderoso, como por ejemplo en el vecino estado de San Luis Potosí. Se nota, entonces, que ni los grandes hacendados ni los caciques políticos son del agrado del autor. Víctor observa que ante los caciques el Estado postrevolucionario fue implacable, minando su base de poder en favor del Estado central. De esta forma, el proceso de centralización del poder político es visto como un proceso virtuoso, en el que no se ven defectos, o por lo menos no se da cuenta de ellos en el libro. 
Con una visión a largo plazo, Víctor argumenta que fue el Estado centralizador postrevolucionario el responsable de que, durante el siglo Xx, haya disminuido en el país la tasa de mortalidad infantil, se haya incrementado la alfabetización, particularmente la femenina, y de que se haya elevado la edad al matrimonio de las mujeres mexicanas. Todos éstos son indicios de cambios sociales, de "la otra revolución" de que nos habla Víctor, de la revolución demográfica, la revolución silenciosa.

De nuevo, Víctor González tiene razón sólo en parte. Yo me pregunto: ¿̨Fueron estos cambios demográficos propiciados por el Estado revolucionario o se hubieran dado aún sin Revolución, como sucedió en otros países de América Latina? Los fenómenos demográficos tienen su especificidad, y eventualmente se manifiestan independientemente de lo que ocurra en las élites políticas. Yo me inclinaría a considerar un poco más la apreciación del demógrafo Eduardo Arriaga, ${ }^{4}$ en el sentido de que el descenso de la mortalidad en México en el siglo XX se debe a un factor de salud pública, es decir, a las nuevas técnicas y descubrimientos médicos, aunque tiene razón Víctor al señalar que de no ser por la organización institucional, los avances médicos no se hubieran propagado con la misma efectividad.
En lo que no estoy de acuerdo es en la idea de que, únicamente se deban al Estado centralizador las mejoras en el sistema de salud. Por ejemplo, en Aguascalientes, para el periodo revolucionario comprendido entre 1910 y 1940, no fue sólo el Estado el encargado de ofrecer servicios de salud. En este periodo, en la atención a la salud y la asistencia social participaron también de manera significativa la iniciativa privada y la Iglesia Católica, esta última a través de los institutos religiosos femeninos, que instalaron hospitales cuando el Estado no podía atender toda la demanda. El Hospital Hidalgo -que era el único que existía entonces en Aguascalientes- era insuficiente. Todavía en 1946 la esposa del gobernador Alberto del Valle pidió ayuda a las religiosas Hijas del Sagrado Corazón de Jesús y Nuestra Señora de Guadalupe para atender dicho hospital. Para el gobierno, esto significaba un ahorro, ya que las religiosas eran responsables, eficientes y no cobraban. Cuando el gobierno estatal pudo hacerse cargo completamente de este hospital, las religiosas establecieron su propia clínica (llamada Clínica Guadalupe).

4. Eduardo Arriaga, New tables for Latin American populations in the nineteenth and twentieth centuries, University of California, Berkeley, 1968. 
Así como estas religiosas, hubo otras que atendieron también dispensarios, asilos de ancianos y orfanatorios. Por otra parte, no creo, como señala el autor, que haya habido un cambio de paradigma, de la beneficiencia a los servicios estatales de salud. La prueba está en que la asistencia social católica coexiste aún con la estatal. Además, el gobierno mexicano, hasta la actualidad, no ha contado en el estado con ningún asilo de ancianos ni orfanatorio. Por otra parte, el Estado mexicano benefactor ha operado también, durante buena parte del siglo Xx, con esquemas asistenciales y paternalistas. En consecuencia, es claro que el Estado se consolidó, pero tenemos que preguntarnos de qué manera.

A pesar del protagonismo que el autor da al Estado mexicano, en momentos parece otorgar un papel más decisivo a los cambios demográficos y, más aún, a factores culturales y familiares como determinantes del progreso social. Así, propone (desde mi punto de vista más acertadamente) que la disminución de la mortalidad y el incremento del alfabetismo y la edad al matrimonio de las mujeres no parece ser producto únicamente de las políticas estatales, sino que son fenómenos que han expresado cambios culturales más profundos en donde el Estado no juega un papel fundamental.
Estoy de acuerdo con el autor en que hay que introducir la dimensión cultural en el análisis de la Revolución Mexicana. Más aún, considero que hay que analizar otro aspecto que Víctor omite en su ensayo: el análisis de la relación entre el Estado postrevolucionario y la democratización de la sociedad mexicana. En este sentido, ha habido regiones -o grandes grupos sociales- que, luego de la Revolución, se han opuesto al proyecto social y al proyecto cultural del Estado revolucionario y que, incluso, hicieron que éste fracasara en ellas. ${ }^{5}$ Por otra parte, el Estado mexicano postrevolucionario, se ha consolidado a lo largo del siglo XX, pero ha tenido momentos de debilidad, pese a lo cual no ha dejado de ser autoritario (por ejemplo la Cristiada). Durante este siglo muchos gobiernos emanados de la Revolución han pospuesto las demandas de justicia social de la misma y, más aún, las demandas de democratización de la sociedad mexicana. Hasta la fecha, pueden cuestionarse los logros alcanzados por el Estado mexicano centralizador, moderno y neoliberal, particularmente en los rubros de justicia social y democratización.

5 Ver Alan Knight, "El proyecto cultural revolucionario" en N. Aguilar, Perspectivas sobre el cardenismo, México, UAM Atzcapotzalco, 1997. 